\title{
ANALISIS PENGARUH BELANJA IKLAN TERHADAP KINERJA PERUSAHAAN DENGAN CORPORATE SOCIAL RESPONSIBILITY SEBAGAI VARIABEL MODERASI
}

\author{
Dyah Rizki Anggita1), Putri Rahayu Kusumawati²) \\ 1) dyahrizkianggitaputri@gmail.com, Politeknik Keuangan Negara STAN \\ 2) jesuisayubelle@pknstan.ac.id, Politeknik Keuangan Negara STAN* \\ *email korespondensi
}

\begin{abstract}
The purpose of this study is to analyse the effect of advertising spending on firm performance as measured by sales and profitability with the disclosure of Corporate Social Responsibility (CSR) as a moderating variable. This study also aims to analyse the effect of advertising spending and CSR disclosure on company performance. This study uses data from 40 companies listed on the Indonesia Stock Exchange in the Consumer Non-Cyclicals sector for the 2015 to 2019 period. This study is a quantitative study using multiple linear regression using the STATA 16 application. The results of this study indicate that advertising spending has a positive and significant effect on company sales, but has no significant effect on profitability. The results of this study also show that CSR does not significantly moderate the relationship between advertising spending and company performance.
\end{abstract}

Keywords: advertising spending, firm performance, CSR.

\begin{abstract}
Abstrak
Penelitian ini bertujuan untuk menganalisis pengaruh belanja iklan terhadap kinerja perusahaan yang diukur dengan penjualan dan profitabilitas perusahaan dengan pengungkapan Corporate Social Responsibility (CSR) sebagai variabel moderasi. Penelitian ini juga bertujuan untuk menganalisis pengaruh belanja iklan dan pengungkapan CSR terhadap kinerja perusahaan. Penelitian ini menggunakan data dari 40 perusahaan yang terdaftar di Bursa Efek Indonesia sektor Consumer Non-Cyclicals pada periode 2015 s.d. 2019. Penelitian ini merupakan penelitian kuantitatif dengan metode regresi linier berganda dengan menggunakan aplikasi STATA 16. Hasil dari penelitian ini menunjukkan bahwa belanja iklan berpengaruh positif dan signifikan terhadap penjualan perusahaan, namun tidak berpengaruh terhadap profitabilitas. Hasil dari penelitian ini juga menunjukkan bahwa CSR memoderasi secara tidak signifikan hubungan belanja iklan dengan kinerja perusahaan.
\end{abstract}

Kata kunci: belanja iklan, kinerja perusahaan, CSR.

\section{PENDAHULUAN}

Kinerja perusahaan merupakan hal yang selalu diperhatikan oleh investor untuk memastikan bahwa modal yang mereka investasikan digunakan dengan baik. Hal tersebut terkait dengan adanya masalah keagenan yang mungkin muncul antara pemilik dan pengelola modal. Masalah kagenan muncul karena terdapat perbedaan kepentingan antara investor (pemilik modal) yang bertindak sebagai prinsipal dan manajer (pengelola modal) yang bertindak sebagai agen (Retno, 2012). Selain itu, kinerja perusahaan yang baik dapat meningkatkan kesejahteraan berbagai pihak, termasuk investor (Taouab dan Issor, 2019).

Kaplan dan Norton (1992) menyebutkan bahwa kriteria pengukuran kinerja terdiri atas aspek keuangan dan nonkeuangan. Dari kedua bentuk pengukuran tersebut, pengukuran kinerja keuangan perusahaan dianggap memberikan hasil yang lebih bermanfaat untuk membantu pemangku kepentingan dalam menganalisis kesehatan keuangan perusahaan (Delen, Kuzay, dan Uyar, 2013). Selain itu, informasi mengenai kinerja keuangan lebih memengaruhi pengambilan keputusan investor dibanding informasi nonkeuangan (Ghosh dan Wu, 2012)

Selain bagi investor, pengukuran kinerja juga penting bagi manajemen dalam mengalokasikan sumber daya perusahaan. Perusahaan akan menggunakan lebih dari satu pengukuran kinerja perusahaan untuk menentukan alokasi berbagai sumber daya (Widener, 2006). Misalnya, apabila perusahaan memberikan perhatian lebih pada sumber daya yang bersifat struktural, perusahaan akan menggunakan pengukuran kinerja yang berkaitan dengan penggunaan tenaga kerja, produktivitas, dan pengukuran kinerja keuangan (Widener, 2006). 


\section{JURNALKU}

Volume 1 No. 4, Desember 2021

Salah satu perusahaan dengan anggaran belanja iklan terbesar, Samsung, menghabiskan 10juta dollar untuk memasang iklan melalui situs Facebook. Iklan tersebut kemudian menghasilkan penjualan sebesar 129juta dollar, hampir tiga belas kali lipat dari belanja iklan yang dikeluarkan (Cohn, 2020). Selain Samsung, perusahaan lain yang melakukan belanja iklan di Facebook dalam jumlah yang besar adalah Ford, yang memiliki pengeluaran untuk iklan sebesar 1,8juta dollar untuk menghasilkan pendapatan sebesar 127juta dollar.

Selain itu, pada masa pandemi COVID-19, berbagai perusahaan meningkatkan anggaran belanja digitalnya, salah satunya adalah Unilever. CEO Unilever, Alan Jope, berencana untuk terus meningkatkan belanja iklan setelah melihat kenaikan sebesar $4.4 \%$ dalam pertumbuhan penjualan. Kenaikan tersebut melampaui ekspektasi yaitu sebesar $1.3 \%$ pertumbuhan penjualan (O'Reilly, 2020).

Belanja iklan di Indonesia terus mengalami peningkatan dari tahun ke tahun. Pada tahun 2019, belanja iklan di Indonesia mencapai Rp181triliun, meningkat 10\% dari tahun sebelumnya (Nielsen, 2020a). Angka tersebut terus meningkat, bahkan pada masa pandemi, terutama untuk iklan digital (Nielsen, 2020b). Menurut press release Nielsen (2020b), kebijakan work from home yang diterapkan selama pandemi mengakibatkan peminat acara TV dan konsumsi digital masyarakat meningkat. Kondisi tersebut kemudian mengakibatkan perusahaan yang termasuk dalam peringkat sepuluh pengiklan tertinggi meningkatkan belanja iklannya melalui TV dan digital.

Besarnya jumlah belanja iklan yang terus meningkat membuat investor dan manajemen berusaha untuk memastikan bahwa terdapat manfaat yang sebanding atas belanja tersebut. Menurut Joshi dan Hanssens (2018), manfaat yang didapat atas belanja iklan terdiri atas manfaat langsung dan tidak langsung. Manfaat langsung adalah dampak yang muncul atas belanja iklan terhadap nilai perusahaan tanpa melalui penjualan dan peningkatan profit. Manfaat tidak langsung adalah dampak belanja iklan terhadap nilai perusahaan melalui penjualan dan peningkatan profit.

Beberapa penelitian terdahulu telah menguji keterlibatan berbagai variabel dalam hubungan belanja iklan dengan kinerja perusahaan. Luo dan de Jong (2012) menggunakan analyst coverage dan earning forecast sebagai variabel mediasi. Assaf et al. (2015) menggunakan Hotel Size dan Star-Rating sebagai variabel moderasi dengan hotel Slovenia dan Kroasia sebagai sampel. Ge, Wang, dan Wang (2017) menggunakan heterogensi kepercayaan investor dan manajer sebagai variabel moderasi hubungan belanja iklan dengan penjualan dan nilai perusahaan yang menunjukkan hasil berlawanan dengan penelitian Sridhar, Narayanan, dan Srinivasan (2014). Berdasarkan pengetahuan penulis, sejauh ini masih jarang ditemui penelitian di Indonesia yang menguji keterlibatan variabel perantara hubungan belanja iklan dengan kinerja perusahaan.

\section{KAJIAN PUSTAKA}

Hubungan antara belanja iklan dengan kinerja perusahaan sudah dibahas dalam berbagai penelitian terdahulu. Berdasarkan penelitian oleh Acar dan Temiz (2017), belanja iklan memberikan dampak positif signifikan terhadap kinerja keuangan sektor perbankan di Turki. Penelitian serupa oleh Sridhar, Narayanan, dan Srinivasan (2014) menunjukkan hubungan positif antara belanja iklan dengan kinerja keuangan perusahaan yang diukur dengan penjualan dan nilai perusahaan. Kim et al. (2018) menunjukkan bahwa belanja iklan berpengaruh positif terhadap penjualan perusahaan, namun berdampak negatif pada profitabilitas dan nilai perusahaan. Namun, dalam penelitian yang lain, Kim et al. (2019) menyimpulkan dampak positif belanja iklan baik terhadap penjualan, profitabilitas, maupun nilai saham perusahaan. 


\section{JURNALKU}

Volume 1 No. 4, Desember 2021

Meski demikian, menurut Luo dan de Jong (2012) masih terdapat missing link dalam hubungan antara belanja iklan dengan kinerja perusahaan. Missing link tersebut dapat mengakibatkan misleading information bagi para pengguna informasi. Hubungan antara belanja iklan dengan kinerja perusahaan merupakan hubungan yang cukup rumit sehingga perlu dilakukan penelitian mengenai variabel lain yang berinteraksi dalam hubungan tersebut (Assaf et al., 2015).

Beberapa penelitian terdahulu telah menguji keterlibatan berbagai variabel dalam hubungan belanja iklan dengan kinerja perusahaan. Luo dan de Jong (2012) menggunakan analyst coverage dan earning forecast sebagai variabel mediasi. Assaf et al. (2015) menggunakan Hotel Size dan Star-Rating sebagai variabel moderasi dengan hotel Slovenia dan Kroasia sebagai sampel. Ge, Wang, dan Wang (2017) menggunakan heterogensi kepercayaan investor dan manajer sebagai variabel moderasi hubungan belanja iklan dengan penjualan dan nilai perusahaan yang menunjukkan hasil berlawanan dengan penelitian Sridhar, Narayanan, dan Srinivasan (2014). Berdasarkan pengetahuan penulis, sejauh ini masih jarang ditemui penelitian di Indonesia yang menguji keterlibatan variabel perantara hubungan belanja iklan dengan kinerja perusahaan.

Berbagai penelitian lain menguji secara lebih khusus keterlibatan pengungkapan CSR sebagai variabel perantara hubungan belanja iklan dengan kinerja perusahaan. Menurut Freeman (1984), CSR dapat menyebabkan minimalisasi konflik potensial antarpemangku kepentingan sehingga mengoptimalkan biaya transaksi. Miller, Eden, dan Li (2020) mengungkapkan bahwa perusahaan yang memiliki reputasi CSR yang lebih dari ketentuan hukum akan menghasilkan kinerja perusahaan yang lebih baik. Meski demikian, simpulan yang berbeda dihasilkan oleh penelitian Ekasari dan Christine (2012) yang menyimpulkan bahwa CSR tidak berpengaruh signifikan terhadap kinerja perusahaan.

Assaf et al. (2017) menguji pengaruh belanja iklan terhadap kinerja perusahaan dengan menggunakan Corporate Social Responsibility (CSR) sebagai variabel moderasi. Dari penelitian tersebut disimpulkan bahwa interaksi CSR dengan belanja iklan berpengaruh positif dan signifikan terhadap kinerja perusahaan. Kondisi tersebut diakibatkan oleh adanya kongruensi informasi yang muncul dari informasi yang disampaikan melalui iklan dan pengungkapan aktivitas CSR yang dilakukan (Assaf et al., 2017). Selain itu, reputasi yang muncul dari pengungkapan aktivitas CSR juga membuat perusahaan lebih mempercayai informasi yang disampaikan dalam iklan yang dilakukan perusahaan (Assaf et al., 2017).

Berbagai penelitian terdahulu dilakukan dengan menggunakan data dari perusahaan di negara maju. Pemangku kepentingan yang berasal dari negara berkembang dapat bereaksi dengan cara yang berbeda terhadap pengungkapan CSR yang merupakan konsep yang relatif baru. Selain itu, penelitian terdahulu banyak menggunakan data dari perusahaan yang bergerak di bidang hospitality atau manufaktur. Sementara itu, penelitian ini menggunakan data dari perusahaan di sektor consumer non-cyclicals.

Moriarty, Mitchell, dan Wells (2015) mendefinisikan iklan sebagai bentuk komunikasi persuasif berbayar yang menggunakan media massa interaktif untuk menghubungkan target audiens dengan pengiklan, menyediakan informasi mengenai suatu produk, dan mengintepretasikan fitur produk sesuai dengan keinginan dan kebutuhan konsumen. Lee dan Johnson (2005) menyebut iklan sebagai bentuk komunikasi berbayar nonpersonal mengenai suatu organisasi dan produk dari organisasi tersebut yang ditransmisikan kepada target audiens melalui media massa. Menurut Richards dan Curran (2002), iklan adalah bentuk komunikasi berbayar melalui media tertentu yang dilakukan oleh pihak tertentu untuk memengaruhi penerima informasi untuk melakukan sesuatu baik sekarang maupun di masa depan. Yadin (2002) mendefinisikan iklan berdasarkan berbagai sudut pandang. Berdasarkan sudut pandang perusahaan yang melakukan iklan, iklan adalah pesan yang paling persuasif yang ditampilkan 


\section{JURNALKU}

Volume 1 No. 4, Desember 2021

untuk menjangkau pelanggan prospektif untuk suatu produk, dengan biaya terendah. Sementara itu, Armstrong (2010) mendefinisikan iklan sebagai semua bentuk tindakan melalui berbagai media yang ditujukan untuk memengaruhi orang lain, baik dengan maupun tanpa motif keuntungan finansial.

Dari berbagai pengertian iklan yang sudah diuraikan, maka dapat disimpulkan bahwa belanja iklan adalah belanja yang dilakukan oleh perusahaan untuk mengirim pesan kepada calon konsumen melalui berbagai media agar konsumen mengetahui informasi mengenai produk dari perusahaan tersebut dan membeli atau menggunakan produk tersebut.

Salah satu alasan utama perusahaan melakukan iklan adalah untuk meningkatkan penjualan (Kim, 1992). Belanja iklan memiliki dampak yang cukup stabil bagi penjualan perusahaan, bahkan pada masa krisis (Sethuraman, Tellis, dan Briesch, 2011). Oleh karena itu, banyak perusahaan yang mengalokasikan belanja iklan dalam jumlah yang cukup besar.

CSR memiliki beberapa definisi. Pasal 1 angka 3 Undang-Undang No. 40 Tahun 2007 tentang Perseroan Terbatas menyatakan:

"Tanggung Jawab Sosial dan Lingkungan adalah komitmen Perseroan untuk berperan serta dalam pembangunan ekonomi berkelanjutan guna meningkatkan kualitas kehidupan dan lingkungan yang bermanfaat, baik bagi Perseroan sendiri, komunitas setempat, maupun masyarakat pada umumnya."

International Council for Ad Self-Regulation (2019) mendefinisikan CSR sebagai inisiatif mandiri oleh organisasi, terutama organisasi berorientasi laba, untuk bertanggung jawab atas dampak dari aktivitas mereka terhadap perekonomian, lingkungan, dan masyarakat. Menurut Beal (2013), CSR secara garis besar adalah kewajiban moral dan praktikal bagi para pelaku pasar untuk mempertimbangkan dampak dari tindakan mereka secara kolektif untuk kemudian melakukan suatu tindakan tertentu untuk menghilangkan dampak tersebut sesuai dengan ekspektasi masyarakat. Menurut Sheehy (2015), CSR adalah tindakan yang dilakukan oleh perusahaan untuk mengurangi dan memitigasi kerusakan yang disebabkan oleh industri serta penyediaan barang publik. Menurut McWilliams dan Siegel (2001), CSR adalah tindakan yang dilakukan oleh perusahaan untuk kebaikan sosial, lebih dari kepentingan perusahaan dan kewajiban hukum. Berdasarkan pengertian yang telah dipaparkan, dapat disimpulkan bahwa CSR adalah upaya perusahaan untuk bertanggung jawab atas dampak yang ditimbulkan dari usahanya, lebih dari yang disyaratkan oleh peraturan atau hukum.

Terdapat berbagai definisi kinerja perusahaan. Menurut Lebas dan Euske (2002), kinerja adalah hal yang dilakukan saat ini oleh manajer untuk menghasilkan perusahaan yang di kemudian hari dapat bekerja sesuai dengan ukuran-ukuran yang telah ditetapkan. Harrison dan Wicks (2013) mendefinisikan kinerja perusahaan sebagai total nilai yang dihasilkan oleh perusahaan melalui berbagai aktivitasnya. Total nilai tersebut merupakan jumlah dari nilai kegunaan yang diciptakan bagi tiap-tiap pemangku kepentingan. Neely, Gregory, dan Platts (1995) mendefinisikan pengukuran kinerja sebagai proses pengukuran baik efisiensi maupun efektivitas dari suatu tindakan. Menurut Selvam et al. (2016), kinerja perusahaan terdiri atas profitabilitas, pertumbuhan, nilai pasar, kepuasan pegawai, kepuasan pelanggan, lingkungan, audit lingkungan, tata kelola perusahaan, dan sosial. Berdasarkan pengertian yang telah diuraikan, dapat disimpulkan bahwa kinerja perusahaan adalah efisiensi dan efektivitas perusahaan dalam berbagai dimensi untuk meningkatkan nilai bagi para pemangku kepentingan.

Dalam penelitian ini, digunakan dua proksi untuk kinerja perusahaan, yaitu penjualan (sales) dan profitabilitas. Penjualan merupakan sumber pendapatan utama bagi hampir seluruh perusahaan, baik berupa barang maupun jasa. Menurut Ivanovic dan Collin (2003), penjualan adalah kegiatan penyerahan suatu barang atau pelaksanaan suatu aktivitas sebagai ganti pemberian uang atau janji pemberian uang. Yadin (2002) menyebutkan bahwa pendapatan 


\section{JURNALKU}

Volume 1 No. 4, Desember 2021

penjualan adalah sinonim dari turnover yang merupakan pendapatan perusahaan atas aktivitas penjualan pada periode tertentu. Berdasarkan penjelasan tersebut, penjualan dapat diartikan sebagai pendapatan atas kegiatan penyerahan suatu barang atau pelaksanaan suatu aktivitas utama perusahaan pada suatu periode tertentu.

Profitabilitas merupakan salah satu tujuan utama perusahaan. Yadin (2002) mendefinisikan profitabilitas sebagai persentase profit yang dihasilkan dari biaya (cost). Tulsian (2009) mendefinisikan profitabilitas sebagai kemampuan suatu investasi untuk memberikan pengembalian atas penggunaan investasi tersebut. Nishantini dan Nimalthasan (2013) memberikan definisi yang sama untuk profitabilitas. Berdasarkan penjabaran tersebut, profitabilitas dapat disimpulkan merupakan tingkat pengembalian yang didapat atas suatu biaya. Menurut Hofstrand (2009), profitabilitas terdiri atas profitabilitas akuntansi dan profitabilitas ekonomi. Profitabilitas akuntansi adalah profitabilitas yang diukur dengan laba bersih. Profitabilitas ekonomi adalah profitabilitas yang diukur dengan mempertimbangkan opportunity cost.

Terdapat berbagai jenis rasio profitabilitas. Menurut Husain dan Sunardi (2020), rasio yang paling banyak digunakan adalah Return on Assets (ROA) dan Return on Equity (ROE). Penelitian ini menggunakan ROA untuk mengukur profitabilitas perusahaan. Menurut Burns (1978), ROA merupakan rasio profitabilitas terbaik karena menggambarkan tingkat pengembalian yang lebih luas.

Teori Sinyal muncul karena adanya asimetri informasi antara perusahaan dengan pasar. Asimetri informasi muncul karena terdapat dua atau lebih pihak yang mengetahui informasi yang berbeda. Banyak pihak kemudian berusaha untuk mengurangi asimetri informasi dengan berbagai cara agar penerima informasi dapat membuat keputusan yang oleh pengirim informasi dianggap benar (Connelly et al., 2011).

Spence (1978) menggunakan pasar tenaga kerja dan proses rekrutmen pegawai untuk menjelaskan asimetri informasi mengenai produktivitas tenaga kerja. Sinyal yang digunakan oleh tenaga kerja untuk produktivitas mereka adalah tingkat pendidikan. Dalam penelitian tersebut, tenaga kerja yang memiliki kualitas produktivitas rendah diasumsikan tidak dapat menempuh pendidikan tinggi.

Nelson (1974) mengungkapkan bahwa perusahaan beriklan bukan untuk memberikan informasi kepada pasar, namun sebagai upaya untuk menjual lebih banyak produk mereka. Mekanisme beriklan dan menjual lebih banyak tersebut mengharuskan perusahaan untuk memberikan informasi kepada pasar dan mengurangi asimetri informasi. Menurut Milgrom dan Roberts (1986), iklan, bersamaan dengan harga barang, merupakan sinyal bagi pelanggan yang menunjukkan kualitas dari suatu produk. Tidak semua iklan mengandung informasi mengenai suatu produk. Suatu iklan dapat memberikan sinyal mengenai kualitas suatu produk dengan memperlihatkan bahwa perusahaan bersedia untuk menghabiskan banyak uang demi mengiklankan produk tersebut.

Freeman (1984) mendefinisikan stakeholder sebagai pihak atau kelompok yang terpengaruh atau dapat memengaruhi tujuan perusahaan. Definisi tersebut dianggap sebagai definisi klasik stakeholder. Definisi lain diberikan oleh David dan David (2017) yang mendefinisikan stakeholder sebagai individu atau kelompok individu yang memiliki klaim terhadap perusahaan.

Assaf et al. (2015) melakukan penelitian untuk menguji pengaruh belanja iklan terhadap penjualan perusahaan. Hasil dari penelitian tersebut menunjukkan bahwa belanja iklan meningkatkan kinerja penjualan perusahaan. Kim et al. (2018) melakukan penelitian serupa untuk menguji pengaruh belanja iklan terhadap kinerja penjualan dengan pendekatan dinamis dan kuadratik. Penelitian tersebut memberikan hasil yang sama yaitu bahwa belanja iklan berpengaruh positif dan signifikan terhadap kinerja penjualan perusahaan. $\mathrm{Hu}, \mathrm{Du}$, dan 


\section{JURNALKU}

Volume 1 No. 4, Desember 2021

Damangir (2014) menjelaskan bahwa belanja iklan memengaruhi penjualan dengan cara meningkatkan minat pelanggan terhadap informasi mengenai produk sebelum membeli produk, kemudian mengubah minat tersebut menjadi penjualan. Berdasarkan uraian tersebut, penulis merumuskan hipotesis sebagai berikut.

$\boldsymbol{H}_{1 a}$ : Belanja iklan berpengaruh positif terhadap penjualan perusahaan.

Selain terhadap penjualan, Kim et al. (2018) juga menguji hubungan belanja iklan terhadap profitabilitas perusahaan. Penelitian tersebut menunjukkan bahwa belanja iklan memberikan dampak positif bagi profitabilitas hingga pada titik optimum. Srivastava, Shervani, dan Fahey (1998) menjelaskan bahwa iklan dapat menghasilkan biaya penjualan yang lebih rendah, menimbulkan price premium, dan menghasilkan competitive barrier yang dapat meningkatkan profitabilitas perusahaan. Oleh karena itu, penulis merumuskan hipotesis sebagai berikut.

$\boldsymbol{H}_{1 b}$ : Belanja iklan berpengaruh positif terhadap profitabilitas perusahaan.

Stakeholder semakin memberi perhatian terhadap tujuan dan tata kelola perusahaan, termasuk mengenai CSR. Hal ini kemudian berpengaruh secara langsung maupun tidak langsung terhadap kinerja keuangan perusahaan (Pan et al., 2014). CSR memengaruhi kinerja keuangan perusahaan karena stakeholder merupakan sumber ekspektasi, penerima dampak, sekaligus pihak yang mengevaluasi kinerja keuangan perusahaan (Wood dan Jones, 2016). Penelitian untuk menguji dampak CSR terhadap performa penjualan perusahaan menunjukkan bahwa CSR berdampak positif terhadap penjualan (Cui, Liang, dan Lu (2015); Nyame-Asiamah dan Ghulam (2019); Waheed dan Yang (2019). Oleh karena itu, penulis merumuskan hipotesis sebagai berikut.

$\boldsymbol{H}_{2 a}$ : Pengungkapan CSR berpengaruh positif terhadap penjualan perusahaan.

Telah terdapat berbagai penelitian yang menyimpulkan bahwa CSR berpengaruh positif terhadap ROA perusahaan (Yang, Bento, dan Akbar (2019); Miller, Eden, dan Li (2020). Penulis merumuskan hipotesis sebagai berikut.

$\boldsymbol{H}_{2 b}$ : Pengungkapan CSR berpengaruh positif terhadap ROA perusahaan.

Individu lebih meyakini kebenaran suatu informasi apabila terdapat dua atau lebih sumber yang memberikan informasi yang sama (Josiasens, Lukas, dan Whitwell, 2008). Pelanggan akan lebih mempercayai sebuah iklan apabila CSR yang diungkapkan sejalan dengan informasi yang terkandung di dalam iklan (Assaf et al., 2017). Reputasi positif yang dihasilkan oleh CSR akan membuat iklan yang dilakukan oleh perusahaan menjadi lebih menarik dan mudah dipercaya. Oleh karena itu, penulis merumuskan hipotesis sebagai berikut. $H_{3 a}$ : Pengungkapan CSR akan memoderasi hubungan belanja iklan dan penjualan secara positif.

Berdasarkan pengembangan hipotesis yang telah dijabarkan dalam H1a, H1b, H2a, $\mathrm{H} 2 \mathrm{~b}$, dan $\mathrm{H} 3 \mathrm{a}$, penulis merumuskan hipotesis sebagai berikut.

$\boldsymbol{H}_{3 b}$ : Pengungkapan CSR akan memoderasi hubungan belanja iklan dan ROA secara positif.

\section{METODE}

Objek yang dipilih penulis dalam penelitian ini adalah perusahaan yang terdaftar di Bursa Efek Indonesia (BEI) selama tahun 2015 s.d. 2019 yang termasuk dalam sektor consumer non-cyclicals atau barang konsumen primer. Menurut klasifikasi industri Bursa Efek Indonesia, sektor barang konsumen primer mencakup perusahaan yang melakukan produksi atau distribusi produk dan jasa yang secara umum dijual pada konsumen yang permintaannya tidak dipengaruhi oleh pertumbuhan ekonomi. Sektor tersebut terdisi atas industri perdagangan ritel barang primer, minuman, makanan olahan, produk makanan pertanian, rokok, produk keperluan rumah tangga, dan produk perawatan tubuh. Penulis memilih sektor tersebut karena berdasarkan siaran pers yang dirilis oleh Nielsen, sejak tahun 2015 s.d. 2019, perusahaan yang 


\section{JURNALKU}

Volume 1 No. 4, Desember 2021

berada pada sektor barang konsumen primer mendominasi peringkat belanja iklan tertinggi. Selain itu, pertumbuhan belanja iklan sektor tersebut juga terus meningkat.

Tahun 2015 s.d. 2019 dijadikan periode penelitian karena Undang-Undang yang mengatur CSR (Undang-Undang Nomor 40 Tahun 2007) mulai berlaku sejak tahun 2007. Selain itu, tahun 2015 s.d. 2019 digunakan sebagai periode penelitian terkait ketersediaan dan kemutakhiran data.

Jenis penelitian ini adalah penelitian kuantitatif. Penelitian kuantitatif adalah penelitian yang menguji hubungan antarvariabel yang diukur secara numerik dan dianalisis menggunakan teknik statistik dan grafik (Saunders, Lewis, dan Thornhill, 2012). Jenis data yang digunakan adalah data sekunder yang bersumber dari laporan tahunan perusahaan yang terdaftar di Bursa Efek Indonesia. Data sekunder adalah data yang telah tersedia dan tidak perlu dikumpulkan sendiri oleh peneliti (Sekaran dan Bougie, 2016).

Metode yang digunakan peneliti dalam pemilihan sampel adalah pemilihan sampel bertujuan (purposive sampling). Purposive sampling adalah teknik penentuan sampel berdasarkan karakteristik yang ditetapkan oleh peneliti yang telah disesuaikan dengan maksud dan tujuan penelitian (Sekaran dan Bougie, 2016). Populasi penelitian adalah perusahaan sektor barang konsumen primer yang terdaftar di Bursa Efek Indonesia (BEI).

Variabel dependen dalam penelitian ini adalah kinerja keuangan perusahaan. kinerja keuangan perusahaan dapat diukur dengan menggunakan beberapa proksi. Carton dan Hover (2010) menyebutkan terdapat sepuluh proksi untuk mengukur kinerja keuangan organisasi, yaitu profit, perubahan profit, pertumbuhan, perubahan pertumbuhan, perubahan nilai ekonomi, perubahan pasar, perubahan arus kas, biaya modal, leverage, dan perubahan ketahanan perusahaan.

Variabel dependen penelitian Assaf et al. (2017) menggunakan proksi penjualan dan nilai perusahaan. Penjualan termasuk dalam proksi pertumbuhan. Nilai perusahaan dapat dikategorikan sebagai perubahan pasar. Penulis menggunakan variabel penjualan dari penelitian tersebut. Penjualan telah digunakan dalam berbagai penelitian terkait sebelumnya (Sridhar, Narayanan, dan Srinivasan, 2014; Kim et al., 2018; Kim, Jun, dan Tang, 2019). Selain itu, pada penelitian ini penulis menggunakan proksi return on asset yang termasuk sebagai proksi profitabilitas. Proksi tersebut digunakan untuk mengidentifikasi dampak variabel independen terhadap profitabilitas yang pada penelitian sebelumnya terdapat hasil yang berbeda (Kim et al., 2018 dan Kim, Jun, dan Tang, 2019).

Variabel independen dalam penelitian ini mengadopsi dari variabel penelitian Assaf et al. (2017) yaitu belanja iklan (advertising spending) yang didapatkan dari database COMPUSTAT. Penelitian ini menggunakan akun beban iklan atau beban promosi yang terdapat di dalam laporan keuangan sebagai penyesuaian. Penggunaan akun dalam laporan keuangan telah dilakukan dalam berbagai penelitian sebelumnya (Luo dan De Jong, 2012; Sridhar, Narayanan, dan Srinivasan, 2014).

Assaf et al. (2017) mengukur variabel ini dengan menggunakan data indeks pengungkapan CSR yang diambil dari COMPUSTAT. Untuk penelitian ini, proksi yang digunakan adalah CSRI (CSR Disclosure Index) dengan indikator GRI (Global Reporting Initiative). Indikator GRI mencakup tiga topik yaitu ekonomi, lingkungan, dan sosial. Indikator GRI merupakan indikator internasional yang telah digunakan oleh perusahaan di dunia. Penelitian lain mengenai pengungkapan CSR telah menggunakan indikator GRI (Hedberg dan Von Malmborg, 2003; Ekasari dan Christine, 2012).

Nilai variabel moderasi diperoleh dengan mencocokkan pengungkapan terkait tanggung jawab sosial perusahaan dalam laporan tahunan dan laporan keberlanjutan perusahaan apabila tersedia. Masing-masing item dicocokkan dengan pengungkapan yang dilakukan oleh perusahaan dengan memberi nilai 1 apabila item diungkapkan dan nilai 0 apabila item tidak 


\section{JURNALKU}

Volume 1 No. 4, Desember 2021

diungkapkan. Total dari item pengungkapan tersebut kemudian dijumlahkan dan dipersentasekan dengan total item yang disyaratkan dalam GRI G4. Terpenuhinya suatu item pengungkapan dinilai secara subjektif oleh penulis dengan menggunakan pembanding (benchmark) dari perusahaan lain yang telah melampirkan checklist indeks GRI G4 dalam laporan keberlanjutannya.

Model penelitian yang diusulkan penulis mengadopsi dari penelitian yang dilakukan oleh Assaf et al. (2017). Model penelitian pertama yang diusulkan adalah untuk menguji hubungan antara belanja iklan, CSR, dan penjualan. Model pertama dirumuskan sebagai berikut.

$$
\text { SALESit }=\alpha 0 \text { it }+\beta 1 \text { ADVit }+\beta 2 \text { GRIit }+\beta 3 \text { SIZEit }+\beta 4 \text { LEVit }+\varepsilon_{-} \text {it }
$$

Untuk melakukan analisis hubungan belanja iklan, CSR, dan profitabilitas, dirumuskan model kedua sebagai berikut.

$$
\text { ROAit }=\alpha 0 \text { it }+\beta 1 \text { ADVit }+\beta 2 \text { GRIit }+\beta 3 \text { SIZEit }+\beta 4 \text { LEVit }+\varepsilon \_ \text {it }
$$

Selanjutnya, model ketiga menguji hubungan belanja iklan dan penjualan dengan CSR sebagai variabel pemoderasi.

$$
\text { SALESit }=\alpha 0 \text { it }+\beta 1 \text { ADVit }+\beta 2 \text { GRIit }+\beta 3 \text { ADVit } * \text { GRIit }+\beta 4 \text { SIZEit }+\beta 5 \text { LEVit }+\varepsilon \_ \text {it }
$$

Model keempat menguji hubungan belanja iklan dan profitabilitas perusahaan dengan CSR sebagai variabel pemoderasi melalui persamaan berikut.

$$
\text { ROAit }=\alpha 0 \text { it }+\beta 1 \text { ADVit }+\beta 2 \text { GRIit }+\beta 3 \text { ADVit } * \text { GRIit }+\beta 4 \text { SIZEit }+\beta 5 \text { LEVit }+\varepsilon \_ \text {it }
$$

Di mana:

SALES : Annual sales

ADV : Belanja iklan

GRI : Nilai indeks GRI perusahaan

SIZE : Ukuran perusahaan

LEV : Leverage

\section{HASIL}

a. Uji Statistik t Model 1

Berdasarkan hasil pengolahan dengan menggunakan software STATA 16, model 1 menggunakan model regresi Fixed Effect Method dengan memberikan perlakuan robust. Hasil uji statistik t dapat dilihat pada tabel 1 berikut ini.

Berdasarkan hasil uji regresi t pada tabel XLIII dapat disimpulkan bahwa variabel belanja iklan (ADV) dan ukuran perusahaan (SIZE) berpengaruh signifikan terhadap variabel dependen penjualan (SALES). Variabel pengungkapan CSR (GRI) dan leverage (LEV) berpengaruh tidak signifikan terhadap variabel dependen penjualan.

Tabel 1. Hasil Uji Statistik t Model 1

\begin{tabular}{ccccc}
\hline Variabel & Coefficient & $\mathbf{t}$ & $\mathbf{P}>|\mathbf{t}|$ & Signifikansi \\
\hline ADV & 1,407277 & 2,43 & 0,020 & Signifikan \\
\hline GRI & 0,7341392 & 1,35 & 0,184 & Tidak signifikan \\
\hline SIZE & $-0,5539746$ & $-3,48$ & 0,001 & Signifikan \\
\hline LEV & $-0,4179046$ & $-1,91$ & 0,064 & Tidak signifikan \\
\hline
\end{tabular}

Sumber: STATA 16 (diolah penulis) 


\section{JURNALKU}

Volume 1 No. 4, Desember 2021

b. Uji Statistik t Model 2

Berdasarkan hasil pengolahan dengan menggunakan software STATA 16, model 2 menggunakan model regresi Fixed Effect Method dengan memberikan perlakuan robust. Hasil uji statistik t dapat dilihat pada tabel 2 di bawah ini.

Tabel 2. Hasil Uji Statisik t Model 2

\begin{tabular}{ccccc}
\hline Variabel & Coefficient & $\mathbf{t}$ & $\mathbf{P}>|\mathbf{t}|$ & Signifikansi \\
\hline ADV & $-1,423497$ & $-1,39$ & 0,173 & Tidak Signifikan \\
\hline GRI & $-0,2224761$ & $-1,40$ & 0,169 & Tidak Signifikan \\
\hline SIZE & $-0,0990979$ & $-0,63$ & 0,532 & Tidak Signifikan \\
\hline LEV & $-0,4616704$ & $-3,14$ & 0,003 & Signifikan
\end{tabular}

Sumber: STATA 16 (diolah penulis)

Berdasarkan hasil uji regresi t pada tabel 2 di atas, dapat disimpulkan bahwa variabel leverage (LEV) berpengaruh signifikan terhadap variabel dependen profitabilitas. Sementara itu, variabel belanja iklan (ADV), pengungkapan CSR (GRI), dan ukuran perusahaan (SIZE) berpengaruh tidak signifikan terhadap variabel dependen profitabilitas.

c. Uji Statistik t Model 3

Berdasarkan hasil pengolahan dengan menggunakan software STATA 16, model 3 menggunakan model regresi Fixed Effect Method dengan memberikan perlakuan robust. Hasil uji statistik t dapat dilihat pada tabel 3 berikut ini.

Berdasarkan hasil uji regresi t pada tabel XLV dapat disimpulkan bahwa variabel belanja iklan (ADV) dan ukuran perusahaan (SIZE) berpengaruh signifikan terhadap variabel dependen penjualan (SALES). Variabel pengungkapan CSR (GRI), leverage (LEV), dan interaksi antara belanja iklan dan pengungkapan CSR (ADVGRI) berpengaruh tidak signifikan terhadap variabel dependen penjualan.

Tabel 3. Hasil Uji Statistik t Model 3

\begin{tabular}{ccccc}
\hline Variabel & Coefficient & $\mathrm{t}$ & $\mathrm{P}>|\mathrm{t}|$ & Signifikansi \\
\hline ADV & 1,880865 & 2,31 & 0,026 & Signifikan \\
\hline GRI & 0,9188848 & 1,67 & 0,104 & Tidak Signifikan \\
\hline SIZE & $-0,5605088$ & $-3,56$ & 0,001 & Signifikan \\
\hline LEV & $-0,4116357$ & $-1,85$ & 0,072 & Tidak Signifikan \\
\hline ADVGRI & $-3,801475$ & $-0,85$ & 0,402 & Tidak Signifikan \\
\hline
\end{tabular}

Sumber: STATA 16 (diolah penulis)

Uji Statistik t Model 4

Berdasarkan hasil pengolahan dengan menggunakan software STATA 16, model 4 menggunakan model regresi Fixed Effect Method dengan memberikan perlakuan robust. Hasil uji statistik t dapat dilihat pada tabel 4 di bawah ini.

Berdasarkan hasil uji regresi t pada tabel XLVI dapat disimpulkan bahwa variabel leverage (LEV) berpengaruh signifikan terhadap variabel dependen profitabilitas (ADV). Variabel belanja iklan (ADV), pengungkapan CSR (GRI), ukuran perusahaan (SIZE), dan interaksi antara belanja iklan dan pengungkapan CSR (ADVGRI) berpengaruh tidak signifikan terhadap variabel dependen profitabilitas. 
Tabel 4. Hasil Uji Statistik t Model 4

\begin{tabular}{ccccc}
\hline Variabel & Coefficient & $\mathrm{t}$ & $\mathrm{P}>|\mathrm{t}|$ & Signifikansi \\
\hline ADV & $-0,1951133$ & $-0,43$ & 0,671 & Tidak Signifikan \\
\hline GRI & 0,2567131 & 0,57 & 0,575 & Tidak Signifikan \\
\hline SIZE & $-0,1160462$ & $-0,68$ & 0,501 & Tidak Signifikan \\
\hline LEV & $-0,4454103$ & $-3,33$ & 0,002 & Signifikan \\
\hline ADVGRI & $-9,86019$ & $-1,12$ & 0,271 & Tidak Signifikan \\
\hline
\end{tabular}

Sumber: STATA 16 (diolah penulis)

\section{HASIL DAN PEMBAHASAN \\ Belanja Iklan Berpengaruh Positif terhadap Penjualan Perusahaan}

Hasil penelitian ini menunjukkan bahwa variabel belanja iklan mempunyai koefisien regresi sebesar 1,407277 dengan nilai probabilitas sebesar 0,020, sehingga dapat disimpulkan bahwa belanja iklan berpengaruh positif dan signifikan terhadap penjualan perusahaan. Oleh karena itu, hipotesis penelitian ini berhasil dibuktikan. Hal ini mengonfirmasi teori pensinyalan yang menyebutkan bahwa perusahaan berusaha mengurangi asymmetric information dengan beriklan (Nelson, 1974, Milgrom dan Roberts, 1986, Assaf et al., 2015, Kim, Jun, dan Tang, 2019). Iklan yang dilakukan perusahaan akan memberi informasi mengenai produk perusahaan sebelum calon konsumen membeli produk tersebut sehingga menimbulkan minat konsumen. Informasi yang terkandung dalam iklan juga akan mengubah minat konsumen tersebut menjadi pembelian yang menghasilkan penjualan bagi perusahaan.

\section{Belanja Iklan Tidak Berpengaruh terhadap Profitabilitas Perusahaan}

Hasil penelitian ini menunjukkan bahwa variabel belanja iklan tidak memiliki kaitan dengan profitabilitas perusahaan. Variabel tersebut memiliki koefisien regresi sebesar 1,423497 dengan nilai probabilitas sebesar 0,173 sehingga hipotesis yang diajukan dalam penelitian ini tidak berhasil dibuktikan. Kim et al. (2018) menjelaskan bahwa kondisi tersebut berkaitan dengan sifat dari industri dalam sampel penelitian. Penelitian ini menggunakan sampel perusahaan consumer non-cyclicals yang dipilih karena memiliki jumlah belanja iklan terbesar di Indonesia. Kondisi tersebut membuat perusahaan-perusahaan dalam sektor consumer non-cyclicals sudah banyak beriklan sehingga dibutuhkan biaya yang cukup besar agar iklan yang dibuat dapat menonjol dibanding iklan perusahaan lain. Hal tersebut kemudian menyebabkan manfaat finansial yang didapatkan dari belanja iklan tidak lebih besar dari biaya yang dikeluarkan. Selain itu, Wang, Zhang, dan Ouyang (2009) menjelaskan bahwa sektor industri dengan belanja iklan yang tinggi jarang menghasilkan permintaan dari pelanggan dalam waktu singkat. Uraian tersebut menjelaskan bukti empiris yang didapatkan dari penelitian ini yaitu bahwa belanja iklan tidak berpengaruh terhadap profitabilitas perusahaan.

\section{Pengungkapan CSR Tidak Berpengaruh terhadap Penjualan Perusahaan}

Hasil penelitian ini menunjukkan bahwa variabel pengungkapan CSR tidak memiliki kaitan dengan penjualan perusahaan. Variabel tersebut memiliki koefisien sebesar 0,7341392 dengan nilai probabilitas sebesar 0,184 sehingga hipotesis yang diajukan dalam penelitian ini tidak dapat dibuktikan. Huber, Pavlíková, dan Basovníková (2017) menjelaskan bahwa kondisi tersebut berkaitan dengan kesadaran masyarakat maupun perusahaan terhadap pentingnya CSR. Hal tersebut juga didukung dengan data pada analisis deskriptif yang menunjukkan bahwa perusahaan pada sampel ini hanya memiliki rata-rata pengungkapan CSR sebesar $18,626 \%$. Nilai tersebut secara relatif lebih rendah dari rata-rata pengungkapan CSR pada negara 


\section{JURNALKU}

Volume 1 No. 4, Desember 2021

berkembang lain seperti Pakistan yang memiliki nilai rata-rata di atas 50\% (Waheed dan Jang, 2019). Uraian tersebut menjelaskan bukti empiris yang didapatkan dari penelitian ini yaitu bahwa pengungkapan CSR tidak berpengaruh terhadap penjualan perusahaan.

\section{Pengungkapan CSR Tidak Berpengaruh terhadap Profitabilitas Perusahaan}

Hasil penelitian ini menunjukkan bahwa variabel pengungkapan CSR tidak memiliki kaitan dengan profitabilitas perusahaan. Variabel tersebut memiliki koefisien sebesar 0,2224761 dengan nilai probabilitas sebesar 0,169 sehingga hipotesis yang diajukan dalam penelitian ini tidak dapat dibuktikan. Aras, Aybars, dan Kutlu (2010) menjelaskan bahwa untuk negara berkembang, pengungkapan CSR belum dapat dikaitkan dengan kinerja keuangan perusahaan. Hal ini berkaitan dengan rendahnya kesadaran perusahaan mengenai potensi pengungkapan CSR untuk meningkatkan profitabilitas perusahaan. Penjelasan tersebut didukung oleh Akinleye dan Faustina (2017) yang menyebutkan bahwa perusahaan yang tidak dapat mengelola belanja sosialnya dengan baik akan menghilangkan kemampuan belanja tersebut untuk menghasilkan profitabilitas. Uraian tersebut menjelaskan bukti empiris yang didapatkan dari penelitian ini yaitu bahwa pengungkapan CSR tidak berpengaruh terhadap profitabilitas perusahaan.

\section{Pengungkapan CSR Tidak Berpengaruh terhadap Hubungan Belanja Iklan dengan Penjualan Perusahaan}

Hasil penelitian ini menunjukkan bahwa variabel pengungkapan CSR tidak memiliki pengaruh signifikan terhadap hubungan belanja iklan dengan penjualan perusahaan. Variabel belanja iklan tidak mengalami perubahan signifikansi setelah berinteraksi dengan variabel pengungkapan CSR. Sebelum berinteraksi dengan pengungkapan CSR, variabel belanja iklan memiliki koefisien sebesar 1,407277 dan probabilitas sebesar 0,020. Setelah berinteraksi dengan pengungkapan CSR, variabel belanja iklan memiliki koefisien sebesar 1,880865 dan probabilitas sebesar 0,026. Muawanah (2020) menjelaskan bahwa sebagian besar perusahaan di Indonesia melaksanakan aktivitas CSR sekadar untuk memastikan bahwa legitimasinya tidak terancam sehingga aktivitas CSR yang dilakukan tidak dikelola dengan baik. Selain itu, Aras, Aybars, dan Kutlu (2010) menjelaskan bahwa pengungkapan CSR pada negara berkembang belum dapat dihubungkan dengan kinerja keuangan perusahaan secara umum. Uraian tersebut menjelaskan bukti empiris yang didapatkan dari penelitian ini yaitu bahwa pengungkapan CSR tidak berpengaruh terhadap hubungan belanja iklan dengan penjualan perusahaan.

\section{Pengungkapan CSR Tidak Berpengaruh terhadap Hubungan Belanja Iklan dengan Profitabilitas Perusahaan}

Hasil penelitian ini menunjukkan bahwa variabel pengungkapan CSR tidak memiliki pengaruh signifikan terhadap hubungan belanja iklan dengan profitabilitas perusahaan. Variabel belanja iklan tidak mengalami perubahan signifikansi setelah berinteraksi dengan variabel pengungkapan CSR. Sebelum berinteraksi dengan pengungkapan CSR, variabel belanja iklan memiliki koefisien sebesar -1,423497 dan probabilitas sebesar 0,173. Setelah berinteraksi dengan pengungkapan CSR, variabel belanja iklan memiliki koefisien sebesar 0,1951133 dan probabilitas sebesar 0,671. Ekasari dan Christine (2012) menjelaskan bahwa hasil tersebut dipengaruhi oleh kondisi perekonomian di Indonesia. Selain itu, Akinleye dan Faustina (2017) menjelaskan bahwa kondisi tersebut juga diakibatkan oleh rendahnya kesadaran perusahaan untuk memaksimalkan kemampuan pengungkapan CSR dalam meningkatkan profit perusahaan. Uraian tersebut menjelaskan bukti empiris yang didapatkan dari penelitian ini yaitu bahwa pengungkapan CSR tidak berpengaruh terhadap hubungan belanja iklan dengan profitabilitas perusahaan. 


\section{JURNALKU}

Volume 1 No. 4, Desember 2021

\section{PENUTUP}

\section{Simpulan}

Belanja iklan berpengaruh positif dan signifikan terhadap penjualan perusahaan, namun tidak berpengaruh signifikan terhadap profitabilitas perusahaan. Pengungkapan CSR tidak berpengaruh terhadap kinerja perusahaan, baik penjualan maupun profitabilitas. Kondisi tersebut menyebabkan tidak terjadinya moderasi oleh pengungkapan CSR terhadap hubungan belanja iklan dengan kinerja perusahaan.

Keterbatasan dalam penelitian ini adalah penggunaan periode penelitian yaitu tahun 2015 sampai dengan 2019. Sementara itu, undang-undang yang mengatur tentang CSR sudah berlaku sejak 2007. Hal ini disebabkan oleh keterbatasan data dan waktu yang dihadapi oleh penulis. Penelitian dapat menghasilkan simpulan yang berbeda apabila dilaksanakan untuk periode yang lebih panjang. Selain itu, penelitian ini tidak memperhitungkan lag atau jarak waktu antara dilakukannya belanja iklan dengan munculnya dampak dari belanja iklan terhadap kinerja iklan.

Penelitian ini mengindikasikan bahwa perusahaan maupun masyarakat Indonesia belum cukup memiliki kesadaran terhadap pentingnya CSR dalam lingkungan operasi perusahaan. Aktivitas CSR bukan hanya bagian dari hal yang harus dilaporkan dalam laporan tahunan sesuai dengan Undang Undang No. 40 Tahun 2007 pasal 66 ayat (2) tentang Perseroan Terbatas, melainkan merupakan bentuk kesadaran perusahaan terhadap dampak aktivitas keseharian perusahaan terhadap lingkungan. Selain itu, pengungkapan CSR memiliki kemampuan untuk meningkatkan profitabilitas perusahaan apabila aktivitas dikelola dengan baik dan diungkapkan dengan komprehensif.

Saran

Berdasarkan hasil penelitian di atas, penulis dapat memberikan saran kepada penulis selanjutya untuk lebih dapat mengembangkan variabel dependen dengan melibatkan data pasar sehingga kinerja keuangan perushaaan dapat diproksikan dengan lebh komprehensif lagi. Selain itu, sektor lain dapat dimungkinkan untuk dimasukkan dalam pembahasan ini dengan syarat konsentrasi belanja iklan yang lebih rendah. Sedangkan saran yang dapat diberikan kepada perusahaan yaitu dengan menumbuhkan kesadaran perusahaan dalam hal pentingnya aktivitas CSR, karena melalui pengungkapan CSR ini diharapkan mampu untuk meningkatkan profitbilitas perusahaan apabila dikelola dengan baik dan diungkapkan dengan lebih komprehensif.

\section{DAFTAR PUSTAKA}

Acar, M., \& Temiz, H. (2017). Advertising effectiveness on financial performance of banking sector: Turkey case. International Journal of Bank Marketing.

Akinleye, G. T., \& Faustina, A. T. (2017). Impact of corporate social responsibility on the profitability of multinational companies in Nigeria. Global Journal of Management and Business Research.

Aras, G., Aybars, A., \& Kutlu, O. (2010). Managing corporate performance: Investigating the relationship between corporate social responsibility and financial performance in emerging markets. International Journal of productivity and Performance management.

Armstrong, J. (2010). Persuasive Advertising: Evidence-based principles (1st ed., p. 3). Basingstoke: Palgrave Macmillan.

Assaf, A. G., Josiassen, A., Ahn, J. S., \& Mattila, A. S. (2017). Advertising spending, firm performance, and the moderating impact of CSR. Tourism Economics, 23(7), 1484-1495.

Assaf, A. G., Josiassen, A., Mattila, A. S., \& Cvelbar, L. K. (2015). Does advertising spending improve sales performance? International Journal of Hospitality Management, 48, 161166. 


\section{JURNALKU}

Volume 1 No. 4, Desember 2021

Barney, J. (1991). Firm resources and sustained competitive advantage. Journal of management, 17(1), 99-120.

Beal, B. D. (2013). Corporate social responsibility: definition, core issues, and recent developments. Sage Publications.

Burns, P. (1987). Financial characteristics of small companies in the UK.

Carton, R. B., \& Hofer, C. W. (2010). Organizational financial performance: Identifying and testing multiple dimensions. Academy of Entrepreneurship Journal, 16(2), 1.

Chung, C. Y., Jung, S., \& Young, J. (2018). Do CSR activities increase firm value? Evidence from the Korean market. Sustainability, 10(9), 3164.

Cohn, R. (2020). How Samsung Turned \$10M in Ads into \$129M in Sales. Retrieved 21 April 2021, from https://sachsmedia.com/how-samsung-turned-10m-in-ads-into-129m-insales/.

Connelly, B. L., Certo, S. T., Ireland, R. D., \& Reutzel, C. R. (2011). Signalling theory: A review and assessment. Journal of management, 37(1), 39-67.

Cooper, D., \& Schindler, P. (2014). Business Research Methods (12th ed., p. 660). New York, N.Y.: McGraw-Hill/Irwin.

Cui, Z., Liang, X., \& Lu, X. (2015). Prize or price? Corporate social responsibility commitment and sales performance in the Chinese private sector. Management and Organization Review, 11(1), 25-44.

David, F., \& David, F. (2017). Strategic Management: A Competitive Advantage Approach, Concepts and Cases (16th ed., p. 664). Essex: Pearson Education Limited.

Delen, D., Kuzey, C., \& Uyar, A. (2013). Measuring firm performance using financial ratios: A decision tree approach. Expert systems with applications, 40(10), 3970-3983.

Doğan, M. (2013). Does firm size affect the firm profitability? Evidence from Turkey. Research Journal of Finance and Accounting, 4(4), 53-59.

Ekasari, N., \& Christine, Y. (2012). Pengaruh Corporate Social Responsibility Terhadap Profitabilitas Pt. Telkom Tbk Sebagai Pemenang Csr Award 2008. AKRUAL: Jurnal Akuntansi, 3(2), 196-208.

Freeman, R. E. (1984). Strategic Management: A Stakeholder Approach. United Kingdom: Pitman.

Ge, J., Wang, G., \& Wang, W. (2017, June). Moderation Effect of Investor and Manager Heterogeneous Beliefs on the Relationship of Advertising and Firm Value. In Academy of Marketing Science World Marketing Congress (pp. 267-277). Springer, Cham.

Ghosh, D., \& Wu, A. (2012). The effect of positive and negative financial and nonfinancial performance measures on analysts' recommendations. Behavioral Research in Accounting, 24(2), 47-64.

Gujarati, D., dan Porter, D. (2009). Basic econometrics (5 ${ }^{\text {th }}$ ed., p.593). New York: McGrawHill/Irwin

Harrison, J. S., \& Wicks, A. C. (2013). Stakeholder theory, value, and firm performance. Business ethics quarterly, 97-124.

Hedberg, C. J., \& Von Malmborg, F. (2003). The global reporting initiative and corporate sustainability reporting in Swedish companies. Corporate social responsibility and environmental management, 10(3), 153-164.

Hill, R., Griffiths, W., \& Lim, G. (2011). Principles of econometrics (4th ed.). Hoboken, NJ: John Wiley \& Sons, Inc.

Holmes, M. J., \& Maghrebi, N. (2015). Reconsidering the role of Tobin's Q. Studies in Economics and Finance.

Hu, Y., Du, R. Y., \& Damangir, S. (2014). Decomposing the impact of advertising: Augmenting sales with online search data. Journal of Marketing Research, 51(3), 300-319. 


\section{JURNALKU}

Volume 1 No. 4, Desember 2021

Huber, P., Pavlíková, E. A., \& Basovníková, M. (2017). The impact of CSR certification on firm profitability, wages and sales (No. 535). WIFO Working Papers.

Husain, T., \& Sunardi, N. (2020). Firm's Value Prediction Based on Profitability Ratios and Dividend Policy. Finance \& Economics Review, 2(2), 13-26.

Ibhagui, O. W., \& Olokoyo, F. O. (2018). Leverage and firm performance: New evidence on the role of firm size. The North American Journal of Economics and Finance, 45, 57-82.

International Council for Ad Self-Regulation. (2019). How self-regulatory advertising standards support Corporate Social Responsibility (CSR). Retrieved from https://icas.global/advertising-standards-and-corporate-social-responsibility/

Isbanah, Y. (2015). Pengaruh ESOP, leverage, and ukuran perusahaan terhadap kinerja keuangan perusahaan di bursa efek Indonesia. Jurnal Riset Ekonomi dan Manajemen, 15(1), 28-41.

Ivanovic, A., \& Collin, P. (2003). Dictionary of Marketing (3rd ed., p. 236). London, UK: Bloomsbury Publishing Plc.

Joshi, A., \& Hanssens, D. M. (2018). The direct and indirect effects of advertising spending on firm value. In LONG-TERM IMPACT OF MARKETING: A Compendium (pp. 521-556).

Josiassen, A., Lukas, B. A., \& Whitwell, G. J. (2008). Country-of-origin contingencies. International Marketing Review, 25(4), 423.

Kaplan, R. S., Norton D. P. (1992). The Balanced Scorecard - Measures that DrivePerformance.

Kim, J., Jun, J., \& Tang, L. R. (2019). How well does advertising work on restaurant performance? A dynamic and quadratic approach. International Journal of Hospitality Management, 81, 11-20.

Kim, J., Jun, J., Tang, L., \& Zheng, T. (2018). The behavioral and intermediate effects of advertising on firm performance: an empirical investigation of the restaurant industry. Journal of Hospitality \& Tourism Research, 42(2), 319-337.

Kim, P. (1992). Does advertising work: A review of the evidence. Journal of Consumer Marketing.

Lee, M., \& Johnson, C. (2005). Principles of Advertising: A Global Perspective (2nd ed., p. 3). New York: Haworth Press.

Lee, S., Upneja, A., Özdemir, Ö., \& Sun, K. A. (2014). A synergy effect of internationalization and firm size on performance. International Journal of Contemporary Hospitality Management.

Lebas, M., \& Euske, K. (2002). A conceptual and operational delineation of performance. Business performance measurement: Theory and practice, 65-79.

Luo, X., \& de Jong, P. J. (2012). Does advertising spending really work? The intermediate role of analysts in the impact of advertising on firm value. Journal of the Academy of Marketing Science, 40(4), 605-624.

Mahendru, M., \& De Kalyan, K. (2014). Does Advertising Expenditure Impact Firm Value: A Case of Indian FMCG Industry. Global Journal of Management And Business Research.

Margaretha, F., \& Witedjo, C. G. (2017). CSR, Nilai Perusahaan dan Kinerja Keuangan Perusahaan pada Industri Pertambangan dan Manufaktur di Indonesia. Media Riset Akuntansi, Auditing \& Informasi, 14(1), 89-114.

McWilliams, A., \& Siegel, D. (2001). Corporate social responsibility: A theory of the firm perspective. Academy of management review, 26(1), 117-127.

Milgrom, P., \& Roberts, J. (1986). Price and advertising signals of product quality. Journal of political economy, 94(4), 796-821.

Miller, S. R., Eden, L., \& Li, D. (2020). CSR reputation and firm performance: A dynamic approach. Journal of Business Ethics, 163(3), 619-636. 


\section{JURNALKU}

Volume 1 No. 4, Desember 2021

Mirza, S. A., \& Javed, A. (2013). Determinants of financial performance of a firm: Case of Pakistani stock market. Journal of economics and International Finance, 5(2), 43-52.

Mitchell, R. K., Agle, B. R., \& Wood, D. J. (1997). Toward a theory of stakeholder identification and salience: Defining the principle of who and what really counts. Academy of management review, 22(4), 853-886.

Moriarty, S., Mitchell, N., \& Wells, W. (2015). Advertising \& IMC (10th ed., p. 36). Harlow: Pearson.

Muawanah, U. (2020). CORPORATE SOCIAL RESPONSIBILITY DAN MOTIVASI PELAPORANNYA: KESADARAN ATAU LEGITIMASI?.e-Repository Dosen Universitas Gajayana Malang.

Neely, A., Gregory, M., \& Platts, K. (1995). Performance measurement system design: a literature review and research agenda. International journal of operations \& production management.

Nelson, P. (1974). Advertising as information. Journal of political economy, 82(4), 729-754.

Nielsen.com a - belanja iklan 2019 ditutup dengan tren positif. (2020). Diakses 20 April 2021, from https://www.nielsen.com/id/id/press-releases/2020/belanja-iklan-2019-ditutupdengan-tren-positif/.

Nielsen.com b - ramadhan di masa pandemi picu perubahan pola konsumsi media dan kreativitas pengiklan. (2020). Retrieved 21 April 2021, from https://www.nielsen.com/id/id/press-releases/2020/ramadhan-di-masa-pandemi-picuperubahan-pola-konsumsi-media-dan-kreativitas-pengiklan/.

Nishanthini, A., \& Nimalathasan, B. (2013). Determinants of profitability: A case study of listed manufacturing companies in Sri Lanka.

Nyame-Asiamah, F., \& Ghulam, S. (2019). The relationship between CSR activity and sales growth in the UK retailing sector. Social Responsibility Journal.

O'Reilly, L. (2020). How the world's biggest advertisers are spending (or not) as industries adapt to the coronavirus pandemic. Retrieved 21 April 2021, from https://digiday.com/marketing/how-the-worlds-biggest-advertisers-are-spending-or-notas-industries-adapt-to-the-coronavirus-pandemic/.

Pan, X., Sha, J., Zhang, H., \& Ke, W. (2014). Relationship between corporate social responsibility and financial performance in the mineral Industry: Evidence from Chinese mineral firms. Sustainability, 6(7), 4077-4101.

Ptok, A., Jindal, R. P., \& Reinartz, W. J. (2018). Selling, general, and administrative expense (SGA)-based metrics in marketing: Conceptual and measurement challenges. Journal of the Academy of Marketing Science, 46(6), 987-1011.

Richards, J. I., \& Curran, C. M. (2002). Oracles on "advertising": Searching for a definition. Journal of Advertising, 31(2), 63-77.

Saunders, M., Lewis, P., \& Thornhill, A. (2012). Research Methods for Business Students (7th ed., p. 166, 179). Harlow: Pearson Education.

Sekaran, U., \& Bougie, R. (2016). Research methods for business (7th ed., p. 37, 248, 655). Chichester: Wiley.

Selvam, M., Gayathri, J., Vasanth, V., Lingaraja, K., \& Marxiaoli, S. (2016). Determinants of firm performance: A Subjective Model. Int'l J. Soc. Sci. Stud., 4, 90.

Sharma, S., Durand, R. M., \& Gur-Arie, O. (1981). Identification and analysis of moderator variabels. Journal of marketing research, 18(3), 291-300.

Sheehy, B. (2015). Defining CSR: Problems and solutions. Journal of business ethics, 131(3), 625-648.

Simbolon, F. (2015). Perbandingan Sistem Pengukuran Kinerja Perusahaan. Binus Business Review, 6(1), 91-100. 


\section{JURNALKU}

Volume 1 No. 4, Desember 2021

Spence, M. (1978). Job market signaling. In Uncertainty in economics (pp. 281-306). Academic Press.

Srivastava, R. K., Shervani, T. A., \& Fahey, L. (1998). Market-based assets and shareholder value: A framework for analysis. Journal of marketing, 62(1), 2-18.

Sethuraman, R., Tellis, G. J., \& Briesch, R. A. (2011). How well does advertising work? Generalizations from meta-analysis of brand advertising elasticities. Journal of Marketing Research, 48(3), 457-471.

Sridhar, S., Narayanan, S., \& Srinivasan, R. (2014). Dynamic relationships among R\&D, advertising, inventory and firm performance. Journal of the Academy of Marketing Science, 42(3), 277-290.

Statista.com. Ford Motor's advertising spending in the U.S. 20 (2021). Diakses 2 November 2021, https://www.statista.com/statistics/261535/ford-motors-advertising-spending-inthe-us/.

Sugiyono. (2013). Metode Penelitian Kuantitatif, Kualitatif, dan R\&D (19th ed., p. 147). Bandung: ALFABETA.

Taouab, O., \& Issor, Z. (2019). Firm performance: Definition and measurement models. European Scientific Journal, 15(1), 93-106.

Tulsian, M. (2014). Profitability Analysis (A comparative study of SAIL \& TATA Steel). IOSR Journal of Economics and Finance, 3(2), 19-22.

Waheed, A., \& Yang, J. (2019). Effect of corporate social responsibility disclosure on firms' sales performance: A perspective of stakeholder engagement and theory. Corporate Social Responsibility and Environmental Management, 26(3), 559-566.

Wang, F., Zhang, X. P. S., \& Ouyang, M. (2009). Does advertising create sustained firm value? The capitalization of brand intangible. Journal of the Academy of Marketing Science, 37(2), 130-143.

Widener, S. K. (2006). Associations between strategic resource importance and performance measure use: The impact on firm performance. Management Accounting Research, 17(4), 433-457.

William, J., \& SANJAYA, R. (2017). Faktor-Faktor Yang Mempengaruhi Kinerja Perusahaan Pada Perusahaan Yang Terdaftar Di Bursa Efek Indonesia. Jurnal Bisnis dan Akuntansi, 19(1a-2), 152-162.

Wood, D. J., \& Jones, R. E. (2016). Stakeholder mismatching: A theoretical problem in empirical research on corporate social performance. In The Corporation and Its Stakeholders (pp. 315-363). University of Toronto Press.

Yadin, D. (2002). The International Dictionary of Marketing (p. 13, 395). London: Kogan Page.

Yang, M., Bento, P., \& Akbar, A. (2019). Does CSR influence firm performance indicators? Evidence from Chinese pharmaceutical enterprises. Sustainability, 11(20), 5656. 